\title{
Biomarcadores associados à defechos clínicos pós- cirurgia cardíaca em terapia intensiva pediátrica
}

Biomarkers associated with postoperative cardiac surgery clinical outcomes in pediatric intensive care

Biomarcadores relacionados con resultados clínicos en el posoperatorio

de cirugía cardíaca en cuidados intensivos pediátricos

Andressa Rodrigues de Souza ${ }^{1}$ io https://orcid.org/0000-0002-2276-8913

Regina Aparecida Garcia de Lima² io https://orcid.org/0000-0002-0611-5621

Luís Carlos Lopes-Júnior ${ }^{3}$ io https://orcid.org/0000-0002-2424-6510

Como citar:

Souza AR, Lima RA, Lopes-Júnior LC. Biomarcadores associados à defechos clínicos pós-cirurgia cardíaca em terapia intensiva pediátrica. Acta Paul Enferm. 2021;34:APE00171.

DOI

http://dx.doi.org/10.37689/actaape/2021AR00171

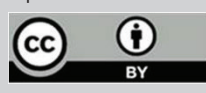

Biomarcadores; Unidades de terapia intensiva pediátrica; Cirurgia cardíaca congênita;

Enfermagem pediátrica

Keywords

Biomarkers; Stress; Pediatric intensive care units Congenital heart surgery; Pediatric nursing

Descriptores

Biomarcadores; Estrés; Unidades de cuidados intensivos pediátricos; Cirugía congénita del corazón; Enfermería pediátrica

\section{Submetido \\ 4 de Fevereiro de 2020 \\ Aceito \\ 1 de Junho de 2020}

\section{Autor correspondente \\ Luís Carlos Lopes-Júnior E-mail: lopesjr.Ic@gmail.com}

\section{Resumo}

Objetivo: Sintetizar e analisar criticamente a literatura a respeito de potenciais biomarcadores associados à desfechos clínicos no pós-operatório de cirurgia cardíaca em lactentes e crianças em cuidados intensivos.

Métodos: Revisão integrativa, cuja busca ocorreu nos meses de setembro e dezembro de 2019, nas bases de dados MEDLINE, ISI of Knowledge, CENTRAL Cochrane, EMBASE, CINAHL, Science Direct e LILACS para responder à questão norteadora: "Quais as evidências científicas acerca de potenciais biomarcadores relacionados à desfechos clínicos no pós-operatório de cirurgia cardíaca de lactentes e crianças em cuidado intensivo?" Foram incluídos artigos originais publicados entre 2000 e 2019, nos idiomas inglês, português ou espanhol. Excluiu-se toda a literatura cinzenta.

Resultados: A amostra final foi constituída por oito artigos, sendo seis estudos observacionais prospectivos descritivos e dois coortes prospectivas. Na maioria dos estudos os pacientes pediátricos foram submetidos à técnica de Bypass Cardiopulmonar (BCP) intraoperatória durante cirurgia de cardiopatia congênita. Os potenciais biomarcadores analisados foram moléculas participantes de processos imune-inflamatórios, predominantemente citocinas pró-inflamatórias tais como IL-1 $\beta$, IL-6, IL-8 e 0 fator de necrose tumoral- $\alpha$ (TNF- $\alpha$ ) e seu receptor, ou citocinas anti-inflamatórias como a IL-10.

Conclusão: As citocinas IL-6, IL-8 e IL-10, o cortisol e o lactato, apresentaram-se como moléculas promissoras para elucidação de mecanismos subjacentes a desfechos clínicos no pós-operatório de cirurgia cardíaca em lactentes e/ou crianças em cuidado intensivo. Tais moléculas podem assumir um caráter preventivo, podendo futuramente ser utilizadas como ferramentas diagnósticas e prognósticas alternativas para um regime que permita identificar pacientes sob alto risco de desenvolver complicações clínicas nos pós-operatórios.

\section{Abstract}

Objective: To summarize and critically analyze the literature on potential biomarkers associated with clinical outcomes in the postoperative cardiac surgery period in infants and children under intensive care.

Methods: Integrative review, whose search was carried out in September and December 2019 in the databases MEDLINE, ISI Web of Knowledge, Cochrane Central Register of Controlled Trials, Embase, Cumulative Index to Nursing and Allied Health Literature, Science Direct, and Latin America and Caribbean Center on Health Sciences Information to answer the following guiding question: "What is the scientific evidence on potential biomarkers associated with clinical outcomes in the postoperative cardiac surgery period in infants and children under intensive care?". Original articles published between 2000 and 2019 in English, Spanish, or Portuguese were included. Gray literature was excluded. 
Results: Eight articles made up the final sample (six descriptive observational prospective studies and two prospective cohort studies). Most studies, pediatric patients were submitted to the intraoperative cardiopulmonary bypass technique during congenital heart disease surgeries. The potential biomarkers analyzed were molecules that participate in immune-inflammatory processes, mainly proinflammatory cytokines such as IL-1 $\beta$, IL-6, IL-8, and tumor necrosis factoralpha and its receptor, as well as anti-inflammatory cytokines such as IL-10.

Conclusion: The IL-6, IL-8, and IL-10 cytokines, cortisol, and lactate showed as promising molecules for elucidating mechanisms underlying clinical outcomes in the postoperative cardiac surgery period in infants and/or children under intensive care. These molecules can take on a preventive role by being used as a diagnostic and prognostic tool in the future in a protocol that allows to identify patients with high risk to develop clinical complications during the postoperative period.

\section{Resumen}

Objetivo: Sintetizar y analizar críticamente la literatura sobre potenciales biomarcadores relacionados con resultados clínicos en el posoperatorio de cirugía cardíaca de lactantes y niños en cuidados intensivos.

Métodos: Revisión integradora, cuya búsqueda ocurrió en los meses de septiembre y diciembre de 2019, en las bases de datos MEDLINE, ISI of Knowledge, CENTRAL Cochrane, EMBASE, CINAHL, Science Direct y LILACS para responder la pregunta orientadora: “¿Cuáles son las evidencias científicas sobre potenciales biomarcadores relacionados con resultados clínicos en el posoperatorio de cirugía cardíaca de lactantes y niños en cuidados intensivos?". Se incluyeron artículos originales publicados entre los años 2000 y 2019, en idioma inglés, portugués o español. Se excluyó toda la literatura gris.

Resultados: La muestra final fue formada por ocho artículos, de los cuales seis eran estudios observacionales prospectivos y dos cohortes prospectivas. En la mayoría de los estudios, los pacientes pediátricos fueron sometidos a la técnica de bypass cardiopulmonar (BCP) intraoperatoria durante la cirugía de cardiopatía congénita. Los potenciales biomarcadores analizados fueron moléculas participantes de procesos inmunoinflamatorios, predominantemente citocinas proinflamatorias tales como IL-1 $\beta, \mathrm{LL}-6, \mathrm{IL}-8$ y el factor de necrosis tumoral- $\alpha$ (TNF- $\alpha$ ) y su receptor, 0 citocinas antinflamatorias como la IL-10.

Conclusión: Las citocinas IL-6, IL-8 e IL-10, el cortisol y el lactato, se presentaron como moléculas promisorias para explicar mecanismos subyacentes de los resultados clínicos en el posoperatorio de cirugía cardíaca de lactantes o niños en cuidados intensivos. Estas moléculas pueden asumir un carácter preventivo y, en un futuro, pueden utilizarse como herramientas alternativas de diagnóstico y pronóstico para un régimen que permita identificar pacientes con alto riesgo de presentar complicaciones clínicas en el posoperatorio.

\section{Introdução}

A cirurgia cardíaca pediátrica é considerada uma das subespecialidades mais complexas da medicina. ${ }^{(1)}$ Particularmente, a doença cardíaca congênita é uma desordem relativamente comum em todo o mundo, afetando entre 4 e 14 indivíduos em cada 1.000 nascidos vivos. ${ }^{(1,2)}$ Cerca de um terço dos lactentes e crianças afetadas necessitam de cirurgia durante a primeira infância. ${ }^{(3,4)}$ Há muitas razóes atreladas às complicações na recuperação pós-operatória de cirurgia cardíaca, especialmente, naquelas associadas a suporte de circulação extracorpórea como o Bypass Cardiopulmonar (BCP). ${ }^{(5,6)}$

Lactentes e crianças submetidas à cirurgia de cardiopatias congênitas, aliada a instabilidade hemodinâmica pós-BCP configura entre as causas de maior risco de morbidade e mortalidade em Unidade de Terapia Intensiva Pediátrica (UTIP). ${ }^{(7)}$ Além disso, BCP pode provocar endotoxemia sistêmica, alteraçôes na permeabilidade capilar, a liberação de citocinas e seus receptores solúveis para a circulação e a ativação da cascata do complemento, resultando em uma resposta inflamatória exacerbada. ${ }^{(8-10)}$ Tal resposta envolve a ativação de linfócitos, monócitos, macrófagos, células endoteliais, bem como de miócitos cardíacos que podem expressar diversas citocinas pró-inflamatórias, incluindo o fator de necrose tumoral (TNF- $\alpha$ ), interleucinas (IL) (IL-1 $\beta$, IL-6, e IL-8), bem como de citocinas anti-inflamatórias como a IL-4, IL-10 e o fator de crescimento transformante (TGF- $\beta$ ). ${ }^{(11-14)} \mathrm{Em}$ adição, a liberação de glicocorticoides como parte da resposta fisiológica do corpo ao estresse cirúrgico, desempenha vários papéis na resposta aguda pós-B$\mathrm{CP}$, os quais modulam a resposta inflamatória do hospedeiro, estimulam a liberação de citocinas anti-inflamatórias, além de desempenharem um papel importante na limitação da permeabilidade capilar bem como na sensibilização de receptores adrenérgicos do miocárdio. ${ }^{(15,16)}$

Estes fatores biologicamente ativos têm sido implicados nas complicaçóes após cirurgia cardíaca, incluindo disfunção pulmonar e atividade contrátil cardíaca deprimida. ${ }^{(17,18)}$ Ademais, a desregulação resultante de vias homeostáticas que regulam a inflamação, metabolismo e sistema endócrino têm consequências clínicas importantes, incluindo má reparação cirúrgica, estado de baixo débito cardíaco persistente, risco para infecção, entre outras morbidades secundárias, podendo culminar em Síndrome de Resposta Inflamatória Sistêmica (SRIS) e até 
mesmo em Síndrome de Disfunção de Múltiplos Órgãos (SDMO). (4,6,19-22) $^{-1}$

Diversos estudos têm demonstrado a ativação da cascata do complemento, a liberação de endotoxina e produção de níveis alterados de citocinas durante e após BCP. ${ }^{(9,10,23-26)}$ Contudo, a capacidade destes estudos em avaliar a correlação com um maior número de mediadores inflamatórios tem sido um tanto limitada, em parte devido ao pequeno tamanho amostral, bem como dada a variabilidade da idade e do diagnóstico. ${ }^{(4,27,28)}$

Neste sentido, uma melhor compreensão da interação entre tal desarranjo homeostático em pacientes pediátricos submetidos a cirurgias cardíacas em cuidado intensivo poderia auxiliar na precisão do diagnóstico e estratificação de pacientes sob-risco aumentado de desenvolver complicações pós-operatórias, por meio da utilização de biomarcadores clinicamente relevantes. ${ }^{(4,29)}$ Nesse contexto, transpóe-se a necessidade de diagnósticos e predição de desfechos clínicos de lactentes e crianças pela aplicação rotineira de tecnologias moleculares como o uso de biomarcadores clinicamente relevantes em cuidado intensivo pediátrico pós-cirúrgico. Assim, o objetivo desta revisão integrativa foi a respeito de potenciais biomarcadores associados à desfechos clínicos no pós-operatório de cirurgia cardíaca em lactentes e crianças em cuidados intensivos.

\section{Métodos}

Realizou-se uma revisão integrativa da literatura. ${ }^{(30)}$ Delimitaram-se as seguintes etapas para o desenvolvimento da pesquisa: a identificação do tema e seleção da questão de pesquisa; o estabelecimento de critérios para inclusão e exclusão de estudos; a definição das informaçóes a serem extraídas dos estudos selecionados; a avaliação dos estudos incluídos na revisão integrativa; a interpretação dos resultados, apresentação da revisão e a síntese do conhecimento. ${ }^{(31)}$

Determinou-se, como tema, potenciais à desfechos clínicos no pós-operatório de cirurgia cardíaca em lactentes e crianças em cuidados intensivos, objetivando responder à seguinte questão norteadora: "Quais as evidências científicas acerca de potenciais biomarcadores associados à desfechos clínicos no pós-operatório de cirurgia cardíaca em lactentes e crianças em cuidados intensivos?". Para a construção da pergunta adequada para a resolução da questão clínica pesquisada, utilizou-se a estratégia $\mathrm{PECO}^{(32)}$ - com "P" correspondendo à população (lactentes e/ou crianças em pós-operatório de cirurgia cardíaca) "E” à exposição (cirurgia cardíaca); "C" à comparação (não se aplica) e "O" correspondendo ao desfecho (desfechos clínicos no pós-operatório de cirurgia cardíaca em UTIP).

Os estudos foram identificados em sete bases de dados eletrônicas: Medical Literature Analysis and Retrieval System Online-MEDLINE via Pubmed, ISI of Knowledge via Web of Science, Cochrane Central Register of Controlled Trials Database-CENTRAL, Cumulative Index to Nursing and Allied Health Literature-CINAHL, EMBASE, Science Direct, Literatura Latino-Americana e do Caribe em Ciências da Saúde-LILACS. Além das bases de dados eletrônicas citadas acima, foram realizadas buscas secundárias em outras fontes diversas, tais como em sites de Registros de Ensaios Clínicos, como, por exemplo, o ClinicalTrials.gov (National Institutes of Health, NIH, USA), The Brazilian Clinical Trials Registry (via Plataforma ReBEC). Ademais, as listas de referências dos estudos primários identificados foram analisadas e examinadas a fim de buscar artigos adicionais relevantes (referências cruzadas). A estratégia de busca avançada foi conduzida nos meses de setembro e dezembro de 2019.

A fim de refletir a prática clínica contemporânea, limitamos a estratégia de busca para estudos publicados a partir de 2000 até dezembro de 2019. Em adição, a estratégia de busca foi restrita a artigos de textos completos publicados nos idiomas inglês, espanhol e português, em revistas científicas que adotam a "revisão por pares" (peer review) de artigos científicos. Adicionalmente, com a finalidade de garantir a sistematização da busca qualificada em termos de organização e manejo de todas as referências recuperadas das bases de dados, utilizamos a ferramenta bibliográfica do EndNote (https://www. myendnoteweb.com/), onde toda a busca foi armazenada e manipulada via online. ${ }^{(33)}$

Inicialmente, foram selecionados descritores dos vocabulários controlados de cada base de dados, tais 
como: (MeSH terms - MEDLINE, CINAHL headings - CINAHL, Emtree terms - EMBASE, e DeCSDescritores em Ciências da Saúde-LILACS) assim como descritores não controlados (palavras-chaves) nas bases Web of Science, CENTRAL Cochrane $e$ Science Direct. Posteriormente, todos os descritores controlados e não controlados foram combinados entre si, da mesma maneira que seus sinônimos, dentro de cada conjunto de termos, por meio de ferramentas de buscas avançadas nas respectivas bases de dados, utilizando-se os conectores booleanos “AND” e “OR”. (34)

Dessa forma, os principais descritores adotados na estratégia de busca foram: ("Biomarkers" $O R$ "Biomarkers, Pharmacological" AND "Stress") AND ("Child" OR "Infant" OR "Pediatrics") AND ("Intensive Care Units, Pediatrics" OR "Critical Care" OR "Critical Illness") AND ("Congenital Heart Disease” OR "Cardiac Surgery" OR "Cardiopulmonary Bypass").

Os critérios de inclusão adotados foram: a) estudos originais cuja temática respondesse à pergunta norteadora, publicados nos idiomas inglês, português ou espanhol, nos últimos 20 anos (2000 a 2019); estudos realizados com lactentes (definido de acordo com o MeSH terms como uma pessoa entre 1 e 23 meses de idade) e/ou crianças (definido de acordo com o MeSH terms como uma pessoa entre 2 e 12 anos de idade) em cuidado intensivo, submetidas a cirurgias cardíacas; estudos cujos desfechos avaliados fossem relacionados à potenciais biomarcadores associados à desfechos clínicos no pós-operatório de cirurgia cardíaca. Excluiu-se toda a literatura cinzenta (publicaçóes como revisão de literatura, dissertaçóes, teses, editoriais, diretrizes clínicas, consensos de especialistas).

Foi realizada leitura exaustiva dos títulos e dos resumos, de forma independente, entre dois autores, para assegurar que os textos contemplavam a pergunta norteadora da revisão e atendiam aos critérios de inclusão estabelecidos. Em caso de dúvida a respeito da seleção, optou-se por incluir, inicialmente, a publicação e decidir sobre sua seleção somente após a leitura na íntegra de seu conteúdo, mediante a apreciação de um terceiro revisor.

Para a extração dos dados foi utilizado como guia um formulário desenvolvido previamente ${ }^{(35)} \mathrm{e}$ adaptado $^{(36)}$ o qual compreende informaçôes distribuídas em quatro domínios: i) identificação do estudo: (título, revista, fator de impacto do periódico, ano de publicação, volume, número, autores, país do estudo, idioma, instituição sede onde o estudo foi conduzido); ii) objetivo e características metodológicas: (questão de pesquisa, objetivo, hipóteses testadas, desenho do estudo, características da amostra - cálculo amostral, descrição do protocolo de coleta de dados, descrição das perdas, instrumentos para coleta de dados e medidas avaliadas, análises estatísticas); iii) resultados/desfechos primários e secundários; e iv) conclusôes e significância clínico-epidemiológica.

O nível de evidência foi identificado com base no delineamento do estudo. Dessa forma, atribuiu-se I para revisóes sistemáticas e metanálise de ensaios clínicos randomizados; II para ensaios clínicos randomizados; III para ensaio controlado não randomizado; IV para estudos caso-controle ou coorte; $\mathrm{V}$ para revisóes sistemáticas de estudos qualitativos ou descritivos; VI para estudos qualitativos ou descritivos e VII para parecer de autoridades e/ou relatórios de comitês de especialistas. Esta hierarquia classifica os níveis I e II como fortes, III a V como moderados e VI a VII como fracos. ${ }^{(37)}$ Ressalta-se que, o nível VII não foi considerado, uma vez que toda a literatura cinzenta foi excluída.

Com relação à avaliação da validade interna e risco de viés dos estudos selecionados, foram utilizadas duas diferentes escalas de avaliação a depender do delineamento do estudo. Para estudos cujo delineamento foi do tipo coorte (prospectivos ou retrospectivos), utilizamos a Newcastle-Ottawa Scale, ${ }^{(38)}$ a qual avalia três domínios: a) seleção dos pacientes - (0 a 4 estrelas); b) comparabilidade dos pacientes nas coortes - (0 a 2 estrelas); e c) desfechos (0 a 3 estrelas). Respostas satisfatórias recebem uma estrela, resultando em um escore máximo possível de 9 estrelas no total. Quanto mais próximo de 9, maior é a qualidade metodológica do estudo e consequentemente, menor é seu risco de viés.

A qualidade metodológica dos estudos observacionais descritivos foi avaliada utilizando a ferramenta de avaliação quantitativa genérica. ${ }^{(39)}$ Esta ferramenta modificada tem 12 critérios que avaliam 
elementos metodológicos dos estudos. A cada reposta afirmativa nessa ferramenta, atribui-se um escore $=1$ e a pontuação total máxima da escala $=12$ é convertida em percentagem (0-100\%). Quanto mais próximo de 12 ou $100 \%$, melhor é a qualidade metodológica do estudo. Ressalta-se que, todas as avaliaçóes referentes à validade interna dos estudos incluídos foram realizadas e confirmadas por dois revisores de modo independente.

A análise dos dados da revisão integrativa foi elaborada de forma descritiva. Utilizou-se um quadro, elaborado pelos autores, para a síntese dos dados de cada estudo primário incluído na revisão, contendo as seguintes informaçóes: citação/ano de publicação e país de origem, objetivos, amostra/média de idade dos participantes, biomarcadores avaliados, protocolo de coleta sanguínea, variáveis clínicas analisadas, principais resultados/conclusôes e nível de evidência. Este quadro permitiu a comparação e a organização dos dados, de acordo as suas diferenças, as similaridades e a pergunta da revisão, os quais foram analisados criticamente e integrados.

\section{Resultados}

Inicialmente, 839 artigos foram identificados nas sete bases de dados e outros seis foram inseridos após buscas secundárias manuais via Google Scholar, ClinicalTrial.gov ou REBEC e/ou nas referências dos artigos primários selecionados (referências cruzadas). Dessa forma, a busca nas bases de dados nos rendeu 833 possíveis estudos após a remoção das 12 duplicatas. A maioria dos estudos foi excluída durante o primeiro "screenning" (804) baseando-se na leitura de títulos e resumos e por não atenderem os critérios de elegibilidade. Vinte e nove artigos foram acessados na íntegra para elegibilidade, dentre os quais oito preencheram todos os critérios de inclusão e compuseram nossa amostra final para extração dos dados e síntese qualitativa (Figura 1).

Com relação à qualidade metodológica dos estudos, observamos que os escores variaram entre moderados e altos, isto é, foram considerados estudos de boa qualidade. Baseando-se na Newcastle-Ottawa Scale, ${ }^{(38)}$ os dois estudos coortes prospectivos apre-

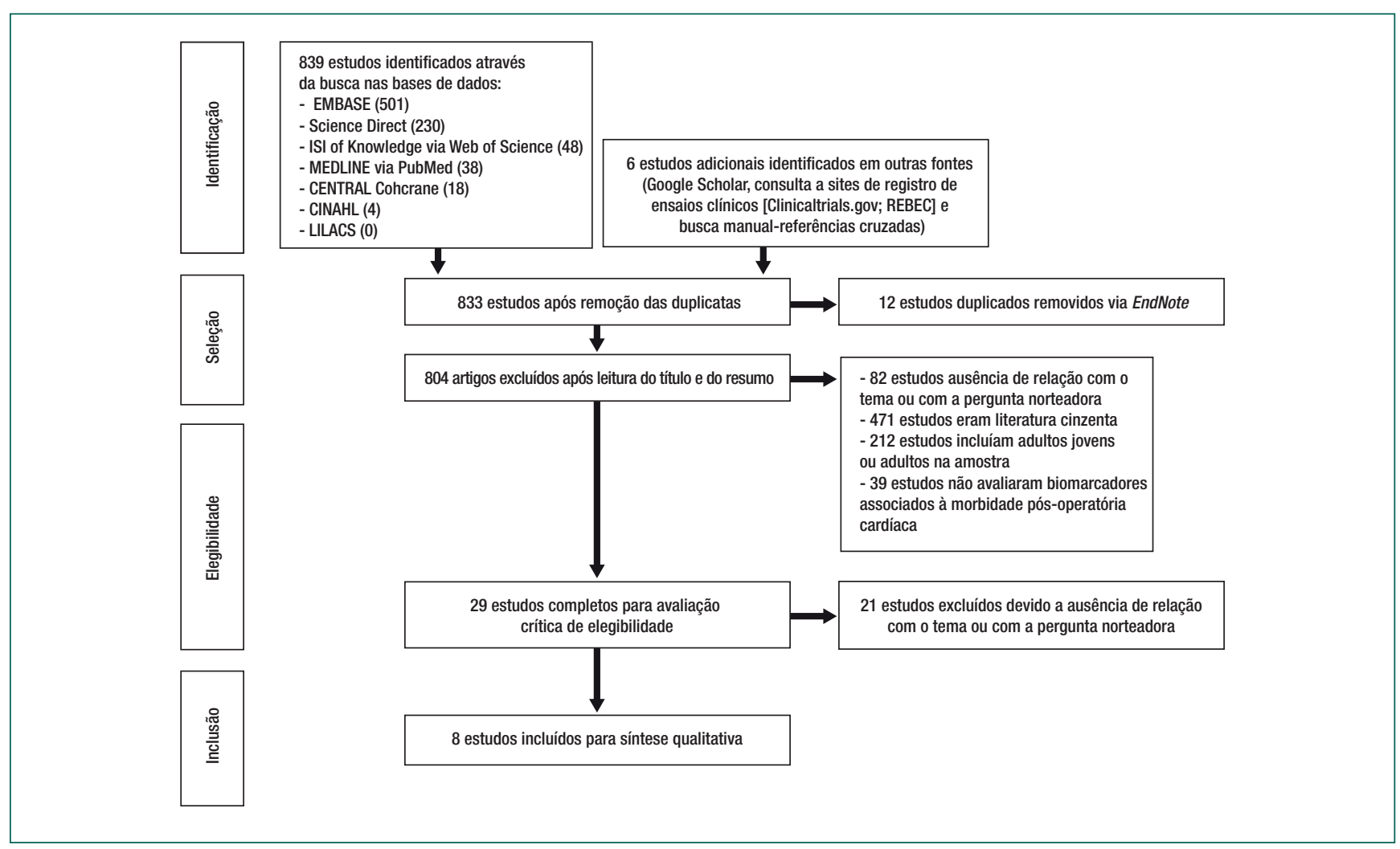

Figure 1. Fluxograma de seleção dos estudos da revisão integrativa 
Quadro 1. Qualidade metodológica dos estudos incluídos na revisão integrativa

\begin{tabular}{|c|c|c|c|c|c|c|c|c|c|c|c|c|c|c|c|}
\hline \multirow{2}{*}{$\begin{array}{l}\text { Estudo/ } \\
\text { Delineamento }\end{array}$} & \multicolumn{14}{|c|}{ Critérios } & \multirow{2}{*}{$\begin{array}{l}\text { Nível de } \\
\text { Evidência }\end{array}$} \\
\hline & 1 & 2 & 3 & 4 & 5 & 6 & 7 & 8 & 9 & 10 & 11 & 12 & Pontuação & $\%$ & \\
\hline $\begin{array}{l}\text { Trotter et al.4(40) } \\
\text { (ODP) }\end{array}$ & $S$ & $S$ & $S$ & $N$ & $S$ & $S$ & NR & $S$ & $S$ & $S$ & NR & $S$ & ag/12 & 75 & $\mathrm{VI}$ \\
\hline $\begin{array}{l}\text { ElBarbary et al. }{ }^{(41)} \\
\text { (ODP) }\end{array}$ & $S$ & $S$ & $S$ & $N$ & $S$ & $S$ & NR & $S$ & $S$ & $S$ & NR & $S$ & ag/12 & 75 & $\mathrm{VI}$ \\
\hline $\begin{array}{l}\text { Madhok et al. }{ }^{(42)} \\
\text { (ODP) }\end{array}$ & $S$ & $S$ & $S$ & $N$ & $S$ & $S$ & $\mathrm{NR}$ & $S$ & $S$ & $S$ & NR & $S$ & ag/12 & 75 & $\mathrm{VI}$ \\
\hline $\begin{array}{l}\text { Allen et al al. }{ }^{(43)} \\
\text { (ODP) }\end{array}$ & $S$ & $S$ & S & $\mathrm{N}$ & $S$ & $S$ & NR & $S$ & $S$ & $S$ & $\mathrm{NR}$ & $S$ & ag/12 & 75 & $\mathrm{VI}$ \\
\hline $\begin{array}{l}\text { Allan et al. }{ }^{(44)} \\
\text { (ODP) }\end{array}$ & $S$ & $S$ & $S$ & $\mathrm{~N}$ & S & S & $\mathrm{NR}$ & $S$ & $S$ & $S$ & $\mathrm{NR}$ & $S$ & ag/12 & 83 & $\mathrm{VI}$ \\
\hline $\begin{array}{l}\text { Crow et al. }{ }^{(45)} \\
\text { (ODP) }\end{array}$ & S & $S$ & S & $\mathrm{N}$ & S & S & $S$ & S & S & $S$ & NR & $S$ & ${ }^{a} 10 / 12$ & 75 & $\mathrm{VI}$ \\
\hline
\end{tabular}

\begin{tabular}{|c|c|c|c|c|c|c|c|c|c|c|}
\hline & \multicolumn{4}{|c|}{ Seleção } & Comparabilidade & \multicolumn{3}{|c|}{ Desfechos } & \multirow[b]{2}{*}{ Pontuação } & \multirow[b]{2}{*}{$\begin{array}{l}\text { Nível de } \\
\text { Evidência }\end{array}$} \\
\hline & $\begin{array}{c}\text { Seleção } \\
\text { da coorte } \\
\text { exposta }\end{array}$ & $\begin{array}{l}\text { Seleção da } \\
\text { coorte não } \\
\text { exposta }\end{array}$ & Exposição & $\begin{array}{c}\text { Resultado } \\
\text { de interesse } \\
\text { não estava } \\
\text { presente no } \\
\text { início } \\
\end{array}$ & $\begin{array}{l}\text { Comparabilidade } \\
\text { de coortes } \\
\text { com base no } \\
\text { delineamento ou } \\
\text { análise } \\
\end{array}$ & $\begin{array}{l}\text { Avaliação do } \\
\text { desfecho }\end{array}$ & $\begin{array}{l}\text { Tempo de } \\
\text { seguimento }\end{array}$ & $\begin{array}{c}\text { Adequação } \\
\text { do } \\
\text { seguimento }\end{array}$ & & \\
\hline $\begin{array}{l}\text { Correia et al. }{ }^{(4)} \\
\text { (CP) }\end{array}$ & $\star$ & $\star$ & $\star$ & & $\star$ & $\star$ & $\star$ & & ${ }^{6} 6 / 9$ & IV \\
\hline $\begin{array}{l}\text { Wald et al. }{ }^{(7)} \\
\text { (CP) }\end{array}$ & $\star$ & $\star$ & $\star$ & & & $\star$ & $\star$ & & ${ }^{\mathrm{b}} 5 / 9$ & IV \\
\hline
\end{tabular}

$\mathrm{ODP}=$ Observacional Descritivo Prospectivo, $\mathrm{CP}=$ Coorte Prospectiva, $(\mathrm{N})=$ Não; $(\mathrm{NR})=$ Não Reportado; $(\mathrm{S})=$ Sim. Critério 1 = 0bjetivo do estudo relatado; 2 = Literatura relevante; 3 = Descrição da amostra; 4 = Justificação do tamanho da amostra; 5 = Medidas de resultados confiáveis e válidas; 6 = Descrição da intervenção; $7=$ Contaminação e co-intervenção; $8=$ Significância estatística; $9=$ Método(s) de análise apropriado (s); $10=$ Importância clínica; 11 = Perdas; 12 = Conclusões apropriadas.. ${ }^{a}$ Escala modificada por Machotka et al.(2009). ${ }^{(39)}$ Esta ferramenta modificada tem 12 critérios que avaliam elementos metodológicos dos estudos. Cada reposta afirmativa nessa ferramenta recebe escore 1 e a pontuação total (0-12) e deve ser convertida em percentagem (0-100\%). ${ }^{\mathrm{b} N e w c a s t l e-O t t a w a}$ Scale, , $^{(38)}$ específica para esse tipo de desenho de estudo. Essa escala é avalia três grandes domínios: seleção dos pacientes - ( 0 a 4 estrelas); comparabilidade dos pacientes nas coortes - $(0$ a 2 estrelas); e desfechos ( 0 a 3 estrelas). Máxima pontuação possível= 9 . Pontuações para estudo coorte e estudos observacionais prospectivos não são diretamente comparáveis

sentaram boa qualidade metodológica, sendo que um apresentou escore $5,{ }^{(7)}$ e outro recebeu escore 6. ${ }^{(4)}$ Os demais estudos observacionais descritivos prospectivos, receberam uma pontuação expressiva, por meio da escala de avaliação genérica adaptada por Machotka et al., ${ }^{(39)}$ sendo que cinco estudos atingiram um escore $9^{(26,40-43)}$ e um estudo atingiu escore $10^{(44)}$ de um total de 12 pontos possíveis (Quadro 1). No que concerne ao risco de viés dos estudos selecionados, observa-se que em praticamente todos os estudos, a confiabilidade dos resultados pode ser um pouco questionada, tanto por risco de viés incerto como por alto risco de viés, particularmente referente aos vícios de seleção (não informação das perdas, ou náo recrutamento de grupo controle adequado), vícios de confusão e dados incompletos de desfechos.

O quadro 2 apresenta em ordem cronológica uma síntese das principais características dos estudos incluídos na análise qualitativa. ${ }^{(4,7,40-45)}$

Os estudos foram publicados entre os anos de 2001 e 2015. (4,7,26,40-43) A metade dos estudos incluídos foi conduzida nos Estados Unidos da América, ${ }^{(7,42,43,44)}$ dois foram realizados no Reino Unido, ${ }^{(4,42)}$ um na Alemanha ${ }^{(40)}$ e outro na Arábia
Saudita. ${ }^{(41)}$ Todos os estudos foram conduzidos em um único centro ou instituição. ${ }^{(4,7,26,40-44)}$

No que concerne ao delineamento metodológico, predominou em nossa amostra os estudos observacionais descritivos prospectivos (seis), ${ }^{(26,40-44)}$ dentre os quais apenas um foi randomizado. ${ }^{(26)}$ Os outros dois estudos foram reportados como sendo coortes prospectivos. ${ }^{(4,7)} \mathrm{O}$ tamanho amostral dos estudos incluídos variou de (18 a 93 pacientes), sendo lactentes ou crianças de ambos os sexos. ${ }^{(4,7,26,40-44)}$ A idade dos lactentes/crianças avaliados nos estudos oscilou de dois dias de vida até 15 anos e todos os participantes das pesquisas foram submetidos à cirurgia corretiva de cardiopatia congênita e cuidados intensivos pós-operatórios em Unidade de Terapia Intensiva Pediátrica (UTIP).

$\mathrm{Na}$ maioria dos estudos (sete), ${ }^{(7,26,40-44)}$ os pacientes pediátricos foram submetidos à técnica de Bypass Cardiopulmonar (BCP) intraoperatória durante cirurgia de cardiopatia congênita e somente em um estudo esta técnica não esteve presente. ${ }^{(4)}$ Diversas doenças congênitas cardíacas foram abordadas nos estudos, tanto as de perfil clínico cianótico como acianótico, tais como: defeito do septo ventricular, insuficiência da artéria pulmonar, dupla 
Quadro 2. Características dos estudos incluídos na revisão integrativa

\begin{tabular}{|c|c|c|c|c|c|c|}
\hline $\begin{array}{l}\text { Referência/ } \\
\text { País }\end{array}$ & Objetivo & $\begin{array}{l}\text { Amostra/ } \\
\text { Média de idade }\end{array}$ & $\begin{array}{l}\text { Biomarcadores } \\
\text { avaliados }\end{array}$ & $\begin{array}{l}\text { Protocolo de } \\
\text { coleta sanguínea }\end{array}$ & $\begin{array}{l}\text { Variáveis } \\
\text { clínicas } \\
\text { analisadas }\end{array}$ & Principais resultados \\
\hline $\begin{array}{l}\text { Trotter et al. }{ }^{(40)} \\
\text { (Alemanha) }\end{array}$ & $\begin{array}{l}\text { Investigar os níveis } \\
\text { plasmáticos da } \\
\text { progesterona e de IL-8 e } \\
\text { IL-10 durante e após BCP } \\
\text { em lactentes/crianças, } \\
\text { em relação ao sexo e } \\
\text { morbidades PO cardíacas }\end{array}$ & $\begin{array}{l}\mathrm{n}=18(10 \mathrm{M} ; 8 \mathrm{~F}) / \\
19 \text { meses } \\
\text { ( } 2 \text { meses a } 15 \\
\text { anos) }\end{array}$ & $\begin{array}{l}\text { Progesterona, IL-8 } \\
\text { e IL-10 }\end{array}$ & $\begin{array}{l}\text { Imediatamente antes da } \\
\text { cirurgia; após indução } \\
\text { anestésica e administração } \\
\text { de heparina; } 10 \text { min. após } \\
\text { o início do BCP; após a } \\
\text { desconexão do circuito e } \\
\text { administração de protamina; } \\
6 \text { h e } 24 \text { h, } 3 \text { e } 7 \text { dias após } \\
\text { a cirurgia }\end{array}$ & $\begin{array}{l}\text { Tempo de BCP, clampe } \\
\text { aórtico, ventilação } \\
\text { mecânica, dias na UTIP e } \\
\text { DMO** }\end{array}$ & $\begin{array}{l}\text { Após BCP todos os pacientes } \\
\text { apresentaram um aumento nos níveis } \\
\text { de progesterona, IL-8 e IL-10, sendo } \\
\text { que a IL-10 foi significativamente maior } \\
\text { nas meninas }(p<0.05) \text {. Seis dentre } 10 \\
\text { meninos e nenhuma menina apresentou } \\
\text { DMO ( } p=0.01) \text {. }\end{array}$ \\
\hline $\begin{array}{l}\text { ElBarbary et } \\
\text { al.(41) } \\
\text { (Arábia } \\
\text { Saudita) }\end{array}$ & $\begin{array}{l}\text { Examinar o comportamento } \\
\text { do receptor de TNF- } \alpha \text { p55 } \\
\text { antes e depois do BCP e a } \\
\text { relação ao desenvolvimento } \\
\text { de citocinemia e } \\
\text { complicações clínicas como } \\
\text { SRIS e DMO** }\end{array}$ & $\begin{array}{l}n=20(12 M ; 8 F) / \\
4.4 \text { anos }\end{array}$ & $\begin{array}{l}\text { IL-1 } \beta \text {, receptores } \\
\text { p55 e p75 de TNF- } \alpha \text {, } \\
\text { TNF- } \alpha, \text { IL-6 e IL-8 }\end{array}$ & $\begin{array}{l}\text { Imediatamente antes do } \\
\text { BCP; } 2 \text { h e } 1 \text { dia após o início } \\
\text { do BCP }\end{array}$ & $\begin{array}{l}\text { Hipotensão; coagulopatia; } \\
\text { disfunção hepática; } \\
\text { disfunção renal; } \\
\text { disfunção respiratória e } \\
\text { extravasamento capilar }\end{array}$ & $\begin{array}{l}\text { Níveis do receptor de TNF p55 } \\
\text { aumentaram significativamente } 2 \mathrm{~h} \\
\text { após BCP e permaneceram por até } \\
1 \text { dia após BCP, se correlacionando } \\
\text { positivamente com a presença de SRIS } \\
(r=0.74, p=0.0001) \text { e DMO }(r=0.84 ; \\
p=0.0007) \text {. Os níveis pré-operatórios } \\
\text { do receptor de TNF p55 foram preditores } \\
\text { de hipotensão, disfunção respiratória e a } \\
\text { coagulopatia nos pacientes }(p<0.005) \text {. }\end{array}$ \\
\hline $\begin{array}{l}\text { Madhok et } \\
\text { al. }{ }^{(42)} \\
\text { (USA) }\end{array}$ & $\begin{array}{l}\text { Mensurar níveis de } \\
\text { citocinas no PO de cirurgia } \\
\text { para cardiopatia congênita e } \\
\text { correlacionar com variáveis } \\
\text { intraoperatórias e desfechos } \\
\text { PO }\end{array}$ & $\begin{array}{l}n=20(11 M ; 9 F) \\
15 \text { meses }(0.1- \\
180)\end{array}$ & $\begin{array}{l}\text { TNF- } \alpha, \text { IL-1 } \beta, \text { IL-12, } \\
\text { IL-6, IL-8 e IL-10 }\end{array}$ & $\begin{array}{l}\text { Pré-operatório (após indução } \\
\text { anestésica). E no P0: } 1 \text { a } \\
3 \text { dias. }\end{array}$ & $\begin{array}{l}\text { Diagnóstico; tempo de BCP; } \\
\text { clampe aórtico; dias na } \\
\text { UTIP; ventilação mecânica; } \\
\text { dias no hospital; escore } \\
\text { inotrópico; saturação } \\
\text { venosa de oxigênio; lactato. }\end{array}$ & $\begin{array}{l}\text { Os níveis de IL-6, IL-8 e IL-10 } \\
\text { aumentaram significativamente no } 1^{\circ} \\
\text { PO }(p<0.01) \text {, sendo que a IL-8 se } \\
\text { correlacionou positivamente com a } \\
\text { necessidade de suporte inotrópico ( } r \\
=0.470 ; p=0.057) \text { e inversamente } \\
\text { com IL-6 ( } r=-0.575 ; p=0.016) \text { e IL-8 } \\
(r=-0.614 ; p=0.009) \text { com o nível de } \\
\text { saturação venosa de oxigênio. }\end{array}$ \\
\hline $\begin{array}{l}\text { Allen et al. }{ }^{(43)} \\
\text { (UK) }\end{array}$ & $\begin{array}{l}\text { Determinar a relação entre } \\
\text { níveis observados de IL-10, } \\
\text { o polimorfismo genético } \\
\text { que influencia esses } \\
\text { níveis e a ocorrência de } \\
\text { hiporresponsividade grave } \\
\text { à endotoxina em crianças } \\
\text { submetidas à cirurgia } \\
\text { cardíaca com uso de BCP }\end{array}$ & $\begin{array}{l}n=36(21 \mathrm{M} ; 15 \mathrm{~F}) \\
6.5 \text { meses ( } 9 \text { dias } \\
\text { a } 24 \text { meses) }\end{array}$ & $\begin{array}{l}\text { IL-10, antagonista do } \\
\text { receptor de IL-1, IL-6, } \\
\text { IL-8; TNF- } \alpha\end{array}$ & $\begin{array}{l}\text { Após a indução anestésica e } \\
\text { inserção do cateter arterial; } \\
\text { na liberação do clampe } \\
\text { aórtico; no final do BCP; após } \\
\text { a ultrafiltração; na chegada à } \\
\text { UTIP; } 2,4,8,14,18,24 \text { e } 48 \text { h } \\
\text { após a admissão na UTIP }\end{array}$ & \begin{tabular}{|l|} 
Duração da ventilação \\
mecânica; dias de \\
internação na UTIP; \\
presença de sepse; \\
imunoparalisia; presença de \\
SRIS e óbito
\end{tabular} & $\begin{array}{l}\text { A resposta das citocinas IL-10 ( } p<0.001) \\
\text { e TNF- } \alpha \quad(p<0.001) \text { e IL-6 }(p<0.05) \\
\text { do sangue a um lipopolissacarídeo foi } \\
\text { reduzida em até } 50 \% \text { no } 1^{\circ} \text { P0 em } \\
\text { relação ao pré-operatório. Imunoparalisia } \\
\text { esteve relacionada, em partes, com altos } \\
\text { níveis de IL-10 circulantes ( } p<0.001) \text {, } \\
\text { colocando os pacientes em alto risco } \\
\text { para complicações no PO. Além disso, } \\
0 \text { genótipo GCC de IL-10 parece ser um } \\
\text { marcador de risco para a imunoparalisia } \\
(p<0.01) \text {. }\end{array}$ \\
\hline $\begin{array}{l}\text { Allan et al.(26) } \\
\text { (USA) }\end{array}$ & $\begin{array}{l}\text { Avaliar a relação entre } \\
\text { o status inflamatório e } \\
\text { desfechos clínicos em } \\
\text { lactentes submetidos a BCP }\end{array}$ & $\begin{array}{l}n=93 \\
(61 \mathrm{M} ; 32 \mathrm{~F}) \\
37 \text { dias } \\
(2-264)\end{array}$ & $\begin{array}{l}\text { PCR, IL-6, IL-8, IL-10, } \\
\text { TNF- } \alpha \text { e IL-1 } \beta\end{array}$ & $\begin{array}{l}\text { Pré-BCP; imediatamente } \\
\text { após o BCP; } 6,12,24 \mathrm{~h} \\
\text { pós-BCP }\end{array}$ & \begin{tabular}{|l|} 
Pré-operatórias: (ex. \\
uso de inotrópicos, \\
ventilação mecânica). \\
Intra-operatórias: (ex. \\
BCP, clampe aórtico, \\
hemoderivados \\
administrados). PO: duração \\
de intubação, tempo de \\
internação na UTIP e no \\
hospital, e concentração \\
de lactato \\
\end{tabular} & $\begin{array}{l}\text { Niveis de IL-6 e PCR pré-BCP foram } \\
\text { maiores em lactentes jovens }(p<0.001) \text {. } \\
\text { Níveis de IL-6, IL-8 e IL-10 aumentaram } \\
\text { no P0, mas, somente IL-6 }(r=0.29 ; \\
p=0.006) \text { e IL-8 }(r=0.30 ; p=0.004) \\
\text { se correlacionaram ao maior tempo de } \\
\text { estadia na UTIP e com a necessidade de } \\
\text { administração de hemoderivados. IL-8 } \\
\text { se correlacionou positivamente com a } \\
\text { concentração de lactato } 24 h \text { pós-cirurgia } \\
(r=0.44 ; p<0.001) \text {. }\end{array}$ \\
\hline $\begin{array}{l}\text { Wald et al. }{ }^{(7)} \\
\text { (USA) }\end{array}$ & $\begin{array}{l}\text { Examinar } 0 \text { efeito de } \\
\text { BCP sobre o eixo HHA, } \\
\text { especificamente na } \\
\text { responsividade adrenal de } \\
\text { lactentes/crianças com } \\
\text { cardiopatia congênita } \\
\text { submetidas à cirurgia }\end{array}$ & $\begin{array}{l}n=52 \\
(25 \mathrm{M} ; 27 \mathrm{~F}) \\
1.6 \text { anos }(0.4- \\
6.5)\end{array}$ & $\begin{array}{l}\text { Cortisol total, cortisol } \\
\text { ligado à globulina, } \\
\text { cortisol livre no soro e } \\
\text { albumina }\end{array}$ & $\begin{array}{l}\text { Pré-operatório (logo após a } \\
\text { incisão do cateter central). } \\
\text { PO: 30min. após cirurgia, } \\
\text { 60min. após a administração } \\
\text { de cosintropina }\end{array}$ & $\begin{array}{l}\text { Escore inotrópico*, índices } \\
\text { hemodinâmicos e o uso de } \\
\text { corticoides suplementares, } \\
\text { escore de risco ajustado } \\
\text { para cirurgia cardíaca, } \\
\text { tempo de ventilação } \\
\text { mecânica, tempo de } \\
\text { internação na UTIP }\end{array}$ & $\begin{array}{l}\text { Níveis diminuídos de cortisol ligado } \\
\text { à globulina foram associados a um } \\
\text { significativo aumento nos níveis de cortisol } \\
\text { livre. Após estimulação com BCP, foram } \\
\text { associados a piores desfechos clínicos, } \\
\text { como um maior tempo de internação } \\
\text { na UTIP ( } p=0.02) \text {, maiores escores } \\
\text { inotrópicos ( } p=0.05) \text {, maior requisição de } \\
\text { soluções isotônicas ( } p=0.007) \text { e tempo } \\
\text { prolongado no respirador }(p=0.013) \text {. }\end{array}$ \\
\hline $\begin{array}{l}\text { Crow et al. }{ }^{(44)} \\
\text { (USA) }\end{array}$ & $\begin{array}{l}\text { Avaliar se há variabilidade } \\
\text { nos níveis de dexametasona } \\
\text { sanguínea após a } \\
\text { administração da dose de } \\
1 \mathrm{mg} / \mathrm{kg} \text { antes do BCP em } \\
\text { lactentes }\end{array}$ & $\begin{array}{l}n=32 \\
(13 M ; 19 F) \\
199 \pm 114 \text { dias } \\
\text { (grupo com nível } \\
\text { baixo de dexa) e } \\
225 \pm 363 \text { (grupo } \\
\text { com nível alto de } \\
\text { dexa) }\end{array}$ & $\begin{array}{l}\text { Dexametasona, } \\
\text { cortisol, ACTH, IL-6, } \\
\text { IL-8 e IL-10 }\end{array}$ & $\begin{array}{l}\text { Após a indução anestésica; } \\
\text { após a ultrafiltração; na } \\
\text { chegada à UTIP; 4, 8, 12 e } \\
\text { 24h após a cirurgia }\end{array}$ & $\begin{array}{l}\text { Escore de risco ajustado } \\
\text { para cirurgia de cardiopatia } \\
\text { congênita; tempo de BCP; } \\
\text { clampe aórtico; escore } \\
\text { inotrópico; tempo de } \\
\text { ventilação mecânica, tempo } \\
\text { de internação na UTIP }\end{array}$ & $\begin{array}{l}\text { A administração de } 1 \mathrm{mg} / \mathrm{kg} \text { de } \\
\text { dexametasona antes da BCP gerou níveis } \\
\text { sanguíneos diferentes de dexametasona } \\
\text { na chegada dos lactentes à UTIP, os quais } \\
\text { foram altamente correlacionados com } \\
\text { a magnitude da resposta ao estresse/ } \\
\text { cortisol no PO ( } \mathrm{p}<0.05) \text {. Pacientes com } \\
\text { altos níveis de dexa apresentaram níveis } \\
\text { de cortisol no PO mais baixos do que seus } \\
\text { níveis no baseline (pré-BCP) ( } p=0.018 \text { ). }\end{array}$ \\
\hline
\end{tabular}




\begin{tabular}{|c|c|c|c|c|c|c|}
\hline $\begin{array}{l}\text { Correia et al. } .^{(4)} \\
\text { (UK) }\end{array}$ & $\begin{array}{l}\text { Avaliar a mudança nos } \\
\text { níveis de metabólitos- } \\
\text { chaves após a cirurgia e } \\
\text { examinar o potencial de } \\
\text { um perfil metabólico na } \\
\text { estratificação de pacientes } \\
\text { em termos de desfechos } \\
\text { clínicos esperados }\end{array}$ & $\begin{array}{l}n=28 \\
(15 \mathrm{M} ; 13 \mathrm{~F}) \\
6.6 \text { meses (4.4- } \\
15.5)\end{array}$ & \begin{tabular}{|l|} 
Antagonista do \\
receptor de IL-1, \\
IL-6, IL-8, IL-10 e \\
metabólitos principais
\end{tabular} & $\begin{array}{l}\text { Pré-operatório (na indução } \\
\text { anestésica). } \\
\text { PO: na admissão à UTIP (zero } \\
\text { hora), 6, } 24 \text { e 28h após a } \\
\text { cirurgia }\end{array}$ & $\begin{array}{l}\text { Escore de risco ajustado } \\
\text { para cirurgia de cardiopatia } \\
\text { congênita; escore de } \\
\text { disfunção de órgãos } \\
\text { pediátricos na admissão } \\
\text { na UTIP; escore inotrópico; } \\
\text { lactato; saturação } \\
\text { arteriovenosa de oxigênio; } \\
\text { número de dias fora da } \\
\text { UTIP }\end{array}$ & $\begin{array}{l}0 \text { controle glicêmico rigoroso não alterou } \\
\text { significativamente o perfil de resposta } \\
\text { dos pacientes no PO. Oito metabólitos } \\
\text { foram associados à gravidade da doença } \\
\text { e gravidade cirúrgica (3-d-hidroxibutirato, } \\
\text { acetona, acetoacetato, citrato, lactato, } \\
\text { creatina, creatinina, e alanina). A } \\
\text { concentração de IL-6 }(r=-0.73 ; \\
p=0.026) \text { e IL- } 8(r=-0.76 ; p=0.017) \\
\text { se correlacionou inversamente com o } \\
\text { número de dias fora da UTIP e a razão } \\
\text { de IL6/L-10 correlacionou positivamente } \\
\text { com o nível de lactato no plasma } \\
(p<0.05) \text {. }\end{array}$ \\
\hline
\end{tabular}

Abreviações: PO = Pós-operatório, BCP = Bypass Cardiopulmonar, PCR = Proteína C-reativa, IL = Interleucina, TNF = Fator de Necrose Tumoral, UTIP = Unidade de Terapia Intensiva Pediátrica, HHA = Hipotálamo-hipófiseadrenal, $\mathrm{ACTH}=$ Hormônio Adrenocorticotrófico, SRIS= Síndrome da Resposta Inflamatória Sistêmica.

*Escore inotrópico $=$ dopamina $\times 1+$ dopamina $\times 1+$ milrinone $\times 15+$ epinefrina $\times 100+$ norepinefrina $\times 100+$ fenilefrina $\times 100$

** DM0=Disfunção de Múltiplos Órgãos (renal, respiratório, hepático, cardíaco, hematológico e neurológico).

saída do ventrículo direito, tetralogia de Fallot, canal atrioventricular, estenose da artéria pulmonar, regurgitação mitral, atresia pulmonar, transposição de grandes artérias, heterotaxia (único ventrículo), dupla entrada do ventrículo esquerdo, síndrome da hipoplasia do coração esquerdo, artéria coronária anômala, defeito do sinus venosus atrial septal, insuficiência/estenose aórtica, retorno venoso pulmonar anômalo total, mixoma, truncus arteriosus, alça da artéria pulmonar, estenose da válvula aórtica, bloqueio atrioventricular completo, coarctaçáo de aorta, forame oval, persistência do canal arterial, defeito do coxim endocárdico e doença coronariana reumática. ${ }^{(4,7,26,40-44)}$

$\mathrm{Na}$ maioria dos estudos (sete), ${ }^{(4,26,40-44)}$ os potenciais biomarcadores analisados foram moléculas participantes de processos imune-inflamatórios, predominantemente citocinas de perfil pró-inflamatório tais como IL-1 $\beta$, IL-6, IL-8, IL-12 e o fator de necrose tumoral- $\alpha$ (TNF- $\alpha$ ) e seu receptor, ou citocinas anti-inflamatórias como a IL-10. Somente um artigo avaliou unicamente um biomarcador hormonal para estresse (cortisol) de modo a refletir a responsividade do eixo HHA (hipotálamo-hipófise-adrenal).(7) Outros dois estudos avaliaram tanto biomarcadores inflamatórios, quanto endócrinos como os hormônios adrenocorticotrófico (ACTH) ${ }^{(44)}$ e progesterona. ${ }^{(40)}$

Nos oito estudos selecionados, os biomarcadores foram avaliados em amostras sanguíneas seguindo o protocolo de coleta pré-operatória e pós-operatória em tempos seriados até o máximo de três dias após a cirurgia, para análises comparativas. A intençấo de tais análises temporais foi avaliar qual o melhor momento para se estimar uma piora clínica do paciente sob o estresse da cirurgia cardíaca e então predizer possíveis complicaçôes clínicas e piores prognósticos.

Desfechos e prognósticos clínicos pós-operatórios foram apontados e correlacionados com os biomarcadores avaliados incluindo: disfunção de múltiplos órgãos (DMO); ${ }^{(40,41)}$ insuficiência adrenal iatrogênica; ${ }^{(44)}$ piora na saturação venosa de oxigênio; ${ }^{(42)}$ maior necessidade de intervenção terapêutica (maior escore terapêutico intervencional), ${ }^{(42)}$ maior escore inotrópico; ${ }^{(7,42)}$ alto risco para a síndrome da resposta inflamatória sistêmica (SRIS); ${ }^{(41)}$ maior tempo de internação na UTIP; ${ }^{(7,26)}$ maior requisiçáo de fluidos; ${ }^{(7)}$ tempo prolongado no respirador; ${ }^{(7)}$ variação no número de dias fora da UTIP; ${ }^{(4)}$ nível aumentado de lactato no plasma; ${ }^{(4,26)}$ necessidade de administração de hemoderivados; ${ }^{(26)}$ imunoparalisia e maior susceptibilidade a infecçôes nosocomiais. ${ }^{(43)}$

\section{Discussão}

O estresse cirúrgico mobiliza uma série de respostas hormonais, metabólicas e imunes, por meio de ativação de vias psiconeuroimunoendócrinas que afetam a homeostasia de pacientes submetidos a esse evento. Foi demonstrado ao longo de décadas passadas que o procedimento cirúrgico pode ativar o eixo hipotalâmico-hipófise-adrenal (HHA), causando uma elevação nos níveis de glicocorticoides sistêmicos. ${ }^{(45)}$ Além disso, recentes estudos mostram níveis significativamente desregulados em uma gama de citocinas pró- e anti-inflamatórias após uma cirur- 
gia, as quais estão diretamente envolvidas na iniciação de uma reação inflamatória aguda e modulação das respostas imunes. ${ }^{(46,47)}$ Entre elas estão a IL-6 como uma representante dos mediadores pró-inflamatórios que regulam positivamente a reação inflamatória aguda, enquanto a IL-10 funciona como uma típica citocina anti-inflamatória para inibir a resposta pró-inflamatória. ${ }^{(12)}$

As cirurgias corretivas de cardiopatias congênitas estão entre as causas de maior estresse da população pediátrica em ambiente hospitalar. $\mathrm{O}$ desafio em lidar com este perfil de cirurgia de grande porte associado à exposição a procedimentos invasivos intraoperatórios como o Bypass Cardiopulmonar (BCP) desencadeia no lactente e criança a susceptibilidade a diversos distúrbios fisiológicos que impactam significantemente na estabilidade pós-operatória. Especificamente sobre o procedimento de BCP, a literatura científica tem investido em pesquisas que abordem os desajustes fisiológicos causados por este insulto ao organismo e o risco para o desenvolvimento de complicaçóes pós-operatórias, piorando o prognóstico das crianças e aumentando os índices de desfechos clínicos desfavoráveis. ${ }^{(7,26,44,48,49)}$ Múltiplos fatores associados ao uso do BCP contribuem para a geração de desregulação imune e favorecimento de um quadro inflamatório agudo, como a ativação celular pelo contato com componentes "estranhos" do BCP;(50) cisalhamento mecânico; ${ }^{(51)}$ reperfusão e isquemia tecidual; ${ }^{(52)}$ hipotensão; ${ }^{(53)}$ perfusão não-pulsátil; ${ }^{(54)}$ hemodiluição com relativa anemia; ${ }^{(55)}$ administração de hemocomponentes el ou hemoderivados; ${ }^{(56)}$ administração de heparina e protamina; ${ }^{(57)}$ e hipotermia. ${ }^{(58)}$

Em nossa revisão observamos a predominância de estudos que abordaram o BCP como indutor de alteraçóes imuno-inflamatórias, as quais foram relacionadas a condiçôes clínicas desfavoráveis como, por exemplo, o maior tempo de estadia na UTIP; $;(4,7,26)$ necessidade de administração de hemoderivados; ${ }^{(26)}$ aumento no nível de lactato pós-cirurgia; ${ }^{(4,26)}$ maiores escores inotrópicos; ${ }^{(7,42)}$ maior requisição de transfusão de fluidos; ${ }^{(7)}$ tempo prolongado no respirador; ${ }^{(7)}$ comprometimento da função cardiopulmonar; ${ }^{(42)}$ imunoparalisia e risco aumentado para infecçôes nosocomiais; ${ }^{(43)}$ hipotensão, disfunção respiratória e coagulopatia; ${ }^{(41)}$ e até à condiçóes graves de saúde, como a Síndrome da Resposta Inflamatória Sistêmica $(\mathrm{SRIS})^{(41)}$ e a Síndrome de Disfunção de Múltiplos Órgãos. ${ }^{(40,41)}$ A relevância de tais estudos esteve focada na identificação de potenciais marcadores biológicos para as alteraçóes clínicas advindas do procedimento cirúrgico cardíaco e do BCP como ferramenta preditiva de desfechos clínicos.

Em se tratando dos desajustes imunológicos causados pelo advento do estresse cirúrgico, as citocinas IL-6, IL-8 e IL-10 se destacaram em cinco estudos selecionados ${ }^{(4,26,40,42,43)}$ como moléculas-chave das respostas a estímulos estressores. As análises de tais estudos demostram o importante papel de sinalização de piora dos quadros clínicos pós-operatórios que estas citocinas modulam, uma vez que houve um aumento nos níveis das citocinas pró-inflamatórias IL-6 e IL-8 pós-BCP, o qual foi significantemente correlacionado ao aumento no tempo de estadia na UTIP, à necessidade de administração de hemoderivados, ao aumento dos níveis de lactato no plasma, à necessidade de maior suporte inotrópico, além de um maior comprometimento da função cardiopulmonar. ${ }^{(4,26,42)}$ Contrariamente, a resposta de IL-10 exacerbada, predispôs os pacientes a quadros de disfunção de múltiplos órgãos ${ }^{(40)} \mathrm{e}$ imunoparalisia. ${ }^{(43)}$

Adicionalmente, o fator de necrose tumoral- $\alpha$ (TNF- $\alpha$ ), completou o quadro das citocinas pró-inflamatórias investigadas como potencial preditivo de complicaçôes clínicas pós-operatórias cardíacas. (26,41-43) Entretanto, foi o seu receptor solúvel, com massa de $55 \mathrm{kD}$ (p55sR) em altos níveis pós-operatórios que efetivamente mostrou estar envolvido em desfechos clínicos desfavoráveis de crianças submetidas a cirurgia de cardiopatia congênita associada ao procedimento de BCP. Altos níveis desse receptor solúvel estiveram associados à predisposição à citocinemia (aumento no número de citocinas e seus receptores na circulação) e ao desenvolvimento de SRIS e da SDMO. Já no pré-operatório, quando presente em altos níveis, esse receptor solúvel correlacionou-se a complicaçóes como hipotensão, disfunção respiratória e coagulopatia. ${ }^{(41)}$

Em relação às alteraçóes no metabolismo de pacientes submetidos a condições estressantes, vários 
estudos destacam metabólitos em níveis alterados que prejudicam o organismo na recuperação a algumas doenças e cirurgias, podendo inclusive levar a condições clínicas de risco de morte. ${ }^{(59-63)}$ Um estudo ${ }^{(4)}$ destacou a necessidade de evidenciar especificamente quais os metabólitos envolvidos nas condiçôes clínicas de crianças submetidas a BCP intraoperatória com a finalidade de predizer piores desfechos clínicos para intervir. Nesse estudo os pesquisadores encontraram que oito metabólitos estavam associados à gravidade da doença cardíaca e à gravidade cirúrgica (o 3-d-hidroxibutirato, a acetona, o acetoacetato, o citrato, o lactato, a creatina, a creatinina, e a alanina). Estes metabólicos foram diretamente associados ao número de dias dos pacientes recebendo cuidados intensivos pediátricos por fora da UTIP, assim como ao escore inotrópico de cada paciente. Em geral, os corpos cetônicos pareciam estar relacionados a desfechos cirúrgicos melhores, enquanto que, o citrato, o lactato, a alanina, a razão creatinina/creatina apresentaram perfil inverso. Os pesquisadores do estudo sugeriram, a partir dos resultados apresentados, que um perfil metabólico poderia ser uma ferramenta clinicamente relevante para a estratificação de pacientes na habilidade de responder positivamente ou negativamente a uma cirurgia de cardiopatia congênita. ${ }^{(4)}$

No que diz respeito às alteraçóes endócrinas e seus efeitos no organismo em resposta a fatores estressantes, os estudos trouxeram a análise de hormônios já bem descritos como participantes de vias neuroendócrinas de ação no estresse, como o cortisol e seu estimulador ACTH, ${ }^{(7,45)}$ assim como a progesterona ${ }^{(40)}$ e suas relaçóes com desfechos clínicos pós-operatórios de cirurgias cardíacas, podendo ser utilizados como importantes biomarcadores na detecção preventiva de complicaçôes fisiológicas.

Os glicocorticoides, em resposta a um estresse cirúrgico, apresentam muitos papéis na resposta à injúria determinada pelo BCP: modulam a resposta inflamatória do organismo, estimulam a liberação de citocinas anti-inflamatórias e limitam a permeabilidade capilar, promovem tônus vasomotor e sensibilizam receptores adrenérgicos do miocárdio. ${ }^{(15,16)}$ Com isso, Crow et $\mathrm{al}^{(44)}$ colocaram em cheque o uso indiscriminado de medicamentos à base de corticoides na pre- venção de processos inflamatórios pós-BCP, quando mostrou que pela administração de uma dose padrão de dexametasona em $1 \mathrm{mg} / \mathrm{kg}$ previamente à cirurgia cardíaca e BCP alteraçóes nos níveis de cortisol pós-operatório eram observadas. Nesse estudo foram reportados que altos níveis de dexametasona estavam associados com a supressão da resposta do cortisol no pós-operatório, predispondo os pacientes a um período de insuficiência adrenal que poderia impactar na estabilidade e recuperação pós-cirúrgica devido à exacerbação das respostas inflamatórias no organismo. Conforme observado em outro trabalho analisado nesta revisão, altos índices de cortisol livre no soro (após estimulação com BCP), foram associados a piores desfechos clínicos pós-operatórios, como um maior tempo de internação dos lactentes e crianças na UTIP, maiores escores inotrópicos, maior requisição de fluidos e tempo prolongado no respirador. ${ }^{(7)}$

Interessantemente, a progesterona, um esteroide sexual com potencial supressor da produção de citocinas pró-inflamatórias, foi analisada em associação à citocina IL-10 para averiguar uma possível diferença sexual na resposta a disfunçóes de múltiplos órgãos (DMO). ${ }^{(40)}$ No entanto, este estudo não observou nenhuma correlação estatisticamente significante entre o hormônio com o quadro de DMO, provavelmente devido o baixo tamanho amostral. Em contrapartida, níveis aumentados de IL-10 nas meninas em relação aos meninos avaliados, promoveram a elas caráter protetor à doença, já que nenhuma menina apresentou DMO, enquanto que, seis de 10 meninos tiveram esta complicação clínica pós-operatória.

Verificamos na presente revisão, a predominância metodológica de estudos observacionais descritivos prospectivos (seis artigos) ${ }^{(39-44)}$ classificados como nível de evidência IV (fracos). ${ }^{(37)}$ Isso chama atenção para a necessidade de condução de ensaios clínicos controlados e randomizados bem delineados e com amostras representativas, com alta validade interna e baixo risco de viés, de modo a permitir que tais evidências focadas na identificação de potenciais biomarcadores clinicamente relevantes a predizer desfechos clínicos, possam ser de fato extrapolados para população de lactentes e crianças submetidas às cirurgias cardíacas e em cuidado intensivo. 
De fato, a maioria dos estudos incluídos trabalhou com amostras pequenas $(\mathrm{n}<30)$, não representativas da população e que não apresentaram o cálculo amostral. Assim, no intuito de minimizar os erros tipo I e tipo II e aumentar a precisão dos resultados encontrados, sugere-se a realização de novos estudos, especialmente ensaios clínicos randomizados com tamanho amostral adequado. Adicionalmente, a maioria dos estudos não apresentou grupo controle, e não informou em sua metodologia a descrição das exclusôes ou perdas dos participantes de pesquisa, o que remete a vícios de seleção presente nesses estudos. Somado às limitaçôes metodológicas, os riscos de viés incerto encontrados nos estudos analisados reduzem a confiabilidade das evidências aqui reunidas, demonstrando a necessidade de estudos futuros experimentais para confirmarem tais resultados. Outras limitaçôes da presente revisão incluem a restrição dos anos de publicação dos estudos (entre 2000 e 2019), uma vez que, poderiam existir estudos anteriores ao início das cirurgias cardíacas e quando se iniciaram as discussões sobre os desfechos clínicos nos pós-operatórios. Assim, os resultados dessa revisão devem ser avaliados com cautela, pois, identificou-se uma diversidade de biomarcadores, protocolos e número de participantes - o que dificulta a generalização dos achados.

A despeito das limitaçóes de cada estudo, esta revisão pôde reunir os principais trabalhos que investigaram potenciais biomarcadores clinicamente relevantes para um possível manejo dos desfechos clínicos no pós-operatório de cirurgias cardíacas em lactentes e/ou crianças em cuidados intensivos. Tais estudos contribuem com avanços diagnósticos e prognósticos, na medida em que podem permitir aos profissionais de saúde de unidades de terapia intensiva pediátrica lidar de maneira mais efetiva na predição de insultos fisiológicos e complicaçóes pós-operatórias passíveis de prevenção, proporcionando maior segurança ao paciente e adequada recuperação.

\section{Conclusão}

O evento cirúrgico cardíaco e o Bypass Cardiopulmonar, muitas vezes requeridos na correção de cardiopatias congênitas em lactentes e crianças, são insultos para o corpo, gerando estresse fisiológico com alteraçóes imunológicas, metabólicas e endócrinas. A análise de potenciais biomarcadores (especialmente as citocinas IL-6, IL-8 e IL-10, o cortisol e lactato) apresenta-se como importantes moléculas protagonistas para elucidar mecanismos subjacentes aos desfechos clínicos no pós-operatório de cirurgias cardíacas em lactentes/ crianças em cuidado intensivo e identificar pacientes sob alto risco de desenvolver complicações clínicas nos pós-operatórios. Tais moléculas podem assumir um caráter preventivo apropriado nestas situaçóes, podendo ser utilizadas futuramente como ferramentas diagnósticas e prognósticas alternativas para um regime preventivo por parte dos profissionais da saúde atuantes em cuidados intensivos pediátricos. Entretanto, estudos adicionais especialmente ensaios clínicos controlados randomizados bem delineados devem ser conduzidos de modo a preencher tal lacuna nessa área de conhecimento, em termos de efetividade, sensibilidade e especificidade dos potenciais biomarcadores clinicamente relevantes aqui reportados.

\section{Referências}

1. Hoffman Jl. The global burden of congenital heart disease. Cardiovasc J Afr. 2013;24(4):141-5.

2. Hoffman Jl, Kaplan S. The incidence of congenital heart disease. J Am Coll Cardiol. 2002;39(12):1890-900.

3. Qu Y, Liu X, Zhuang J, Chen G, Mai J, Guo X, et al. Incidence of Congenital Heart Disease: The 9-Year Experience of the Guangdong Registry of Congenital Heart Disease, China. PLoS One. 2016;11(7):e0159257.

4. Correia GD, Wooi Ng K, Wijeyesekera A, Gala-Peralta S, Williams R, MacCarthy-Morrogh S, et al. Metabolic profiling of children undergoing surgery for congenital heart disease. Crit Care Med. 2015;43(7):146776.

5. Brown KL, Ridout DA, Goldman AP, Hoskote A, Penny DJ. Risk factors for long intensive care unit stay after cardiopulmonary bypass in children. Crit Care Med. 2003;31(1):28-33.

6. Pagowska-Klimek I, Pychynska-Pokorska M, Krajewski W, Moll JJ. Predictors of long intensive care unit stay following cardiac surgery in children. Eur J Cardiothorac Surg. 2011;40(1):179-84.

7. Wald EL, Preze E, Eickhoff JC, Backer CL. The effect of cardiopulmonary bypass on the hypothalamic-pituitary-adrenal axis in children. Pediatr Crit Care Med. 2011;12(2):190-6.

8. Hoffman TM, Wernovsky G, Atz AM, Kulik TJ, Nelson DP, Chang AC, et al. Efficacy and safety of milrinone in preventing low cardiac output syndrome in infants and children after corrective surgery for congenital heart disease. Circulation. 2003;107(7):996-1002. 
9. Tárnok A, Schneider P. Pediatric cardiac surgery with cardiopulmonary bypass: pathways contributing to transient systemic immune suppression. Shock. 2001;16 Suppl 1:24-32.

10. Paśnik J. [The significance of neutrophil in inflammatory response after cardiac surgery with cardiopulmonary bypass]. Wiad Lek. 2007;60(34):171-7.

11. Gessler P, Pfenninger J, Pfammatter JP, Carrel T, Baenziger 0, Dahinden C. Plasma levels of interleukin-8 and expression of interleukin-8 receptors on circulating neutrophils and monocytes after cardiopulmonary bypass in children. J Thorac Cardiovasc Surg. 2003;126(3):718-25.

12. Gessler P, Pretre R, Hohl V, Rousson V, Fischer J, Dahinden C. CXCchemokine stimulation of neutrophils correlates with plasma levels of myeloperoxidase and lactoferrin and contributes to clinical outcome after pediatric cardiac surgery. Shock. 2004;22(6):513-20.

13. Qing $M$, Schumacher $K$, Heise R, Wöltje M, Vazquez-Jimenez JF, Richter T, et al. Intramyocardial synthesis of pro- and anti-inflammatory cytokines in infants with congenital cardiac defects. J Am Coll Cardiol. 2003;41(12):2266-74.

14. Goldszmid RS, Trinchieri G. The price of immunity. Nat Immunol. 2012;13(10):932-8.

15. Suominen PK, Dickerson HA, Moffett BS, Ranta SO, Mott AR, Price $\mathrm{JF}$, et al. Hemodynamic effects of rescue protocol hydrocortisone in neonates with low cardiac output syndrome after cardiac surgery. Pediatr Crit Care Med. 2005;6(6):655-9.

16. Kilger E, Weis F, Briegel J, Frey L, Goetz AE, Reuter D, et al. Stress doses of hydrocortisone reduce severe systemic inflammatory response syndrome and improve early outcome in a risk group of patients after cardiac surgery. Crit Care Med. 2003;31(4):1068-74.

17. de Mendonça-Filho HT, Gomes RV, de Almeida Campos LA, Tura B, Nunes EM, Gomes R, et al. Circulating levels of macrophage migration inhibitory factor are associated with mild pulmonary dysfunction after cardiopulmonary bypass. Shock. 2004;22(6):533-7.

18. Stayer SA, Diaz LK, East DL, Gouvion JN, Vencill TL, McKenzie ED, et al. Changes in respiratory mechanics among infants undergoing heart surgery. Anesth Analg. 2004;98(1):49-55.

19. Brown MD, Wernovsky G, Mussatto KA, Berger S. Long-term and developmental outcomes of children with complex congenital heart disease. Clin Perinatol. 2005;32(4):1043-57.

20. Snookes SH, Gunn JK, Eldridge BJ, Donath SM, Hunt RW, Galea MP, et al. A systematic review of motor and cognitive outcomes after early surgery for congenital heart disease. Pediatrics. 2010;125(4):e818-27.

21. Horeczko T, Green JP, Panacek EA. Epidemiology of the Systemic Inflammatory Response Syndrome (SIRS) in the emergency department. West J Emerg Med. 2014;15(3):329-36.

22. Seymour CW, Liu VX, Iwashyna TJ, Brunkhorst FM, Rea TD, Scherag A, et al. Assessment of Clinical Criteria for Sepsis: For the Third International Consensus Definitions for Sepsis and Septic Shock (Sepsis-3). JAMA. 2016;315(8):762-74.

23. Paparella D, Yau TM, Young E. Cardiopulmonary bypass induced inflammation: pathophysiology and treatment. An update. Eur J Cardiothorac Surg. 2002;21(2):232-44.

24. Ben-Abraham R, Weinbroum AA, Dekel B, Paret G. Chemokines and the inflammatory response following cardiopulmonary bypass - a new target for therapeutic intervention?-A review. Paediatr Anaesth. 2003;13(8):655-61.

25. Levy JH, Tanaka KA. Inflammatory response to cardiopulmonary bypass. Ann Thorac Surg. 2003;75(2):S715-20.
26. Allan CK, Newburger JW, McGrath E, Elder J, Psoinos C, Laussen $P C$, et al. The relationship between inflammatory activation and clinical outcome after infant cardiopulmonary bypass. Anesth Analg. 2010;111(5):1244-51.

27. Alcaraz AJ, Manzano L, Sancho L, Vigil MD, Esquivel F, Maroto E, et al. Different proinflammatory cytokine serum pattern in neonate patients undergoing open heart surgery. Relevance of IL-8. J Clin Immunol. 2005;25(3):238-45.

28. Schumacher K, Korr S, Vazquez-Jimenez JF, von Bernuth G, Duchateau $J$, Seghaye MC. Does cardiac surgery in newborn infants compromise blood cell reactivity to endotoxin? Crit Care. 2005;9(5):R549-55.

29. Goddard SL, Adhikari NK. The Challenging Task of Improving the Recovery of ICU Survivors. JAMA. 2016;315(24):2671-2.

30. Whittemore R, Knafl K. The integrative review: updated methodology. J Adv Nurs. 2005;52(5):546-53.

31. Mendes KD, Silveira RC, Galvão CM. Revisão integrativa: método de pesquisa para a incorporação de evidências na saúde e na enfermagem. Texto Contexto Enferm. 2008;17(4):758-64.

32. Morgan RL, Whaley P, Thayer KA, Schünemann HJ. Identifying the PECO: A framework for formulating good questions to explore the association of environmental and other exposures with health outcomes. Environ Int. 2018;121(Pt 1):1027-31.

33. Carlos L. Lopes-Júnior, Cruz LA, Leopoldo VC, Campos FR, Almeida AM, Silveira RC. Effectiveness of traditional chinese acupuncture versus sham acupuncture: a systematic review. Ver Lat Am Enfermagem. 2016;24:e2762.

34. Lopes-Júnior LC, Rosa MA, Lima RA. Psychological and Psychiatric Outcomes Following PICU Admission: A Systematic Review of Cohort Studies. Pediatr Crit Care Med. 2018;19(1):e58-67.

35. Ursi ES, Gavão CM. [Perioperative prevention of skin injury: an integrative literature review]. Rev Lat Am Enfermagem. 2006;14(1):124-31. Portuguese.

36. Lopes-Júnior LC, Bomfim EO, Nascimento LC, Nunes MD, Pereira-daSilva G, Lima RA. Non-pharmacological interventions to manage fatigue and psychological stress in children and adolescents with cancer: an integrative review. Eur J Cancer Care (Engl). 2016;25(6):921-35.

37. Melnyk BM, Fineout-Overholt E. Evidence-based practice in nursing \& healthcare. A guide to best practice. China: Wolters Kluwer/Lippincott Williams \& Wilkins; 2011.

38. Wells GA, Shea B, O'Connell D, et al. The Newcastle-Ottawa Scale (NOS) for assessing the quality of nonrandomized studies in metaanalyses. Ottawa (ON): Ottawa Hospital Research Institute; 2011. [cited 2015 Sep 30]. Available at http://www.ohri.ca/programs/ clinical_epidemiology/oxford.htm

39. Machotka Z, Kumar S, Perraton LG. A systematic review of the literature on the effectiveness of exercise therapy for groin pain in athletes. Sports Med Arthrosc Rehabil Ther Technol. 2009;1(1):5.

40. Trotter A, Mück K, Grill HJ, Schirmer U, Hannekum A, Lang D. Genderrelated plasma levels of progesterone, interleukin-8 and interleukin-10 during and after cardiopulmonary bypass in infants and children. Crit Care. 2001;5(6):343-8.

41. el-Barbary M, Khabar KS. Soluble tumor necrosis factor receptor p55 predicts cytokinemia and systemic inflammatory response after cardiopulmonary bypass. Crit Care Med. 2002;30(8):1712-6.

42. Madhok AB, Ojamaa K, Haridas V, Parnell VA, Pahwa S, Chowdhury D. Cytokine response in children undergoing surgery for congenital heart disease. Pediatr Cardiol. 2006;27(4):408-13. 
43. Allen ML, Hoschtitzky JA, Peters MJ, Elliott M, Goldman A, James I, et al. Interleukin-10 and its role in clinical immunoparalysis following pediatric cardiac surgery. Crit Care Med. 2006;34(10):2658-65.

44. Crow SS, Oliver WC Jr, Kiefer JA, Snyder MR, Dearani JA, Li Z, et al. Dexamethasone levels predict cortisol response after infant cardiopulmonary bypass. J Thorac Cardiovasc Surg. 2014;147(1):47581 .

45. Nakamura M, Suita S, Yamanouchi T, Masumoto K, Ogita K, Taguchi $S$, et al. Cortisol and cytokine responses after surgery in different age groups of pediatric patients. Pediatr Surg Int. 2003;19(3):194-9.

46. Li Y, Yuan Q, Huang J, Li YP, Pan J, Feng X, et al. Assessment of plasma B7-H3 levels in pediatric patients with different degrees of surgical stress. BMC Pediatr. 2016;16(1):110.

47. Gentile LF, Moldawer LL. HMGB1 as a therapeutic target for sepsis: It's all in the timing. Expert Opin Ther Targets. 2014; 18(3:243-245.

48. Checchia PA, Bronicki RA, Costello JM, Nelson DP. Steroid use before pediatric cardiac operations using cardiopulmonary bypass: an international survey of 36 centers. Pediatr Crit Care Med. 2005;6(4):441-4.

49. Kozik DJ, Tweddell JS. Characterizing the inflammatory response to cardiopulmonary bypass in children. Ann Thorac Surg. 2006;81(6):S2347-54.

50. Brix-Christensen $\mathrm{V}$. The systemic inflammatory response after cardiac surgery with cardiopulmonary bypass in children. Acta Anaesthesiol Scand. 2001;45(6):671-9.

51. Seghaye MC. The clinical implications of the systemic inflammatory reaction related to cardiac operations in children. Cardiol Young. 2003;13(3):228-39.

52. Chugani HT. Biological basis of emotions: brain systems and brain development. Pediatrics. 1998;102(5 Suppl E):1225-9.

53. Vidal Melo MF. Clinical respiratory physiology of the neonate and infant with congenital heart disease. Int Anesthesiol Clin. 2004;42(4):29-43.
54. Bestic M, Reed MD. The ontogeny of human kidney development: influence on neonatal diuretic therapy. Neoreviews. 2005;6(8):e3638.

55. Ulrichs F, Speer CP. Neutrophil function in preterm and term infants. Neoreviews. 2004;5(10):e417-30.

56. Chenoweth DE, Cooper SW, Hugli TE, Stewart RW, Blackstone EH, Kirklin JW. Complement activation during cardiopulmonary bypass: evidence for generation of C3a and C5a anaphylatoxins. N Engl J Med. 1981;304(9):497-503.

57. Kirklin JK, Westaby S, Blackstone EH, Kirklin JW, Chenoweth DE, Pacifico AD. Complement and the damaging effects of cardiopulmonary bypass. J Thorac Cardiovasc Surg. 1983;86(6):845-57.

58. Kirklin JK, Chenoweth DE, Naftel DC, Blackstone EH, Kirklin JW, Bitran $\mathrm{DD}$, et al. Effects of protamine administration after cardiopulmonary bypass on complement, blood elements, and the hemodynamic state. Ann Thorac Surg. 1986;41(2):193-9.

59. Suhre K. Metabolic profiling in diabetes. JEndocrinol. 2014;221(3):R7585.

60. Mirnezami R, Kinross JM, Vorkas PA, Goldin R, Holmes E, Nicholson $\mathrm{J}$, et al. Implementation of molecular phenotyping approaches in the personalized surgical patient journey. Ann Surg. 2012;255(5):8819 .

61. Mickiewicz B, Vogel HJ, Wong HR, Winston BW. Metabolomics as a novel approach for early diagnosis of pediatric septic shock and its mortality. Am J Respir Crit Care Med. 2013;187(9):967-76.

62. Langley RJ, Tsalik EL, van Velkinburgh JC, Glickman SW, Rice BJ, Wang $C$, et al. An integrated clinico-metabolomic model improves prediction of death in sepsis. Sci Transl Med. 2013;5(195):195ra95.

63. Mickiewicz B, Duggan GE, Winston BW, Doig C, Kubes P, Vogel $\mathrm{HJ}$; Alberta Sepsis Network. Metabolic profiling of serum samples by $1 \mathrm{H}$ nuclear magnetic resonance spectroscopy as a potential diagnostic approach for septic shock. Crit Care Med. 2014;42(5):1140-9. 